\title{
RSP Revisitada
}

É difícil ignorar um autor como Guerreiro Ramos. Como intelectual, nunca deixou de expressar firmemente suas posições, envolvendo-se em diversas polêmicas com figuras como Costa Pinto, Roger Bastide, Florestan Fernandes, entre outros. Sua trajetória profissional e política é tão grande quanto as polêmicas nas quais se envolveu: professor, pesquisador, deputado federal (PTB da Guanabara), militante do movimento negro, nacionalista, integralista (na juventude), técnico em administração do Departamento Administrativo do Serviço Público (Dasp). Foi também professor em instituições brasileiras e nos Estados Unidos.

No Dasp, o autor inteirou-se da problemática do Brasil e da administração pública brasileira. Sua preocupação residia na inadequação dos modelos importados para entender a realidade brasileira. Por isso, segundo o autor, teríamos que forjar instrumentos teóricos próprios, adequados a nossa realidade social.

Guerreiro Ramos ingressou no Dasp em 1945, e nesta ocasião apresentou o trabalho revisitado nesta seção. Neste texto está presente a preocupação do pensador com a construção de uma teoria que orientasse a prática da administração: "Sem uma teoria, jamais a administração poderá tomar forma e facilmente se converte em débil presa do oportunismo".

Guerreiro Ramos faleceu em 6 de abril de 1982, em Los Angeles, Califórnia. A Revista do Serviço Público não poderia deixar de lembrar, nos 30 anos do aniversário de sua morte, de um dos seus mais ilustres colaboradores.

\section{Administração e política à luz da sociologia}

Guerreiro Ramos

Texto publicado na RSP, vol. 3, no 1, de junho de 1946

A concepção sociológica, indispensável em se tratando de questões do homem e da sociedade,

é, nas suas aplicações aos problemas da Administração, uma das orientações mais modernas, profundas e frutuosas.

Dai a importância do presente ensaio que, situando-se na corrente de Karl Mannheim, tem como objetivo específico o de estabelecer uma distinção sociológica entre a Política e a 
Administração, e, pràticamente, sugerir um caminho para evitar o conflito entre ambas.

Seu autor, Sr. Guerreiro Ramos, é um jovem sociólogo que se vem firmando com trabalhos reputados, pela crítica mais autorizada do país, como contribuicõoes de valor cientifico. Professor de Sociologia da Universidade da Babia, cargo de que se ach a afastado atualmente, o Sr. Guerreiro Ramos é, talvez, no Brasil, a maior autoridade em assuntos sociológicos de puericultura, matéria que constitui o objeto de curso que ministra anualmente, com reconhecido sucesso, no Departamento NacionaI da Criança e sôbre a qual publicou "Aspectos Sociológicos da Puericultura", em cuja reprodução se interesson o Bureau de Educação da Liga das Nações", "Uma Concepção Multidimensional do Comportamento", "As Implicações Sociológicas da Puericultura." e, como coautor, "Um Inquérito Sôbre Quinhentos $\mathrm{Me}$ nores". E ainda autor de "Introducão à Cultura", incluido na seleta de livros latino-americanos da Pan American Union, além de numerosos ensaios esparsos em revistas e jornais.

O Prof. Guerreiro Ramos dirigirá, a partir do próximo mês, a seção de crítica desta Revista, o que, certamente, fará dentro de ampla perspectiva, graças aos seus conhecimentos filosóficos e sociológicos, tanto quanto à sua experiência administrativa. (N. R.).

Entre os muitos modos de distinguir a administração da política $^{1}$, o sociológico é, certamente, um dos mais fecundos e mais adequados às exigências da fase atual do mundo contemporâneo. O presente modo sociológico de vêr a sociedade é o que a considera como um proces$\mathrm{so}^{2}$, isto é, o que a considera como algo em mudança, em devenir, e não como um conjunto de instituições naturais, estabelecidas de urna vez por tôdas. A visão quietista da sociedade é característica da mentalidade primitiva e das épocas em que a elaboração da concepção do mundo está monopolizada por uma minoria esclarecida, épocas, portanto, das quais o presente estádio de nossa civilização está muito longe.

A persistência do conceito quietista da sociedade é uma sobrevivência. Ela é responsável pela demora com que se operam certas transformações necessárias para que a sociedade atual se ajuste a imperativos recem-aparecidos na história e que exigem um tratamento não-dogmático, não-teológico, mas sociológico. Não se trata de um imperialismo da sociologia, mas, de um lado, do fato de ser a sociologia a ciência social por excelência, aquela que possui a perspectiva mais ampla e, de outro lado, de uma razão de estrutura ${ }^{3}$, enquanto a sociologia é fruto da descrença na bondade inquestionável, na eternidade das instituições e na definitiva estabilidade social.

O reconhecimento da precariedade fundamental de qualquer tipo de organização social deve advertir o administrador contra o perigo de uma técnica ou ciência da administração que se pretenda auto-suficiente e capaz de resolver tôdas as questões que emergem da realidade social. O sucesso da administração depende de sua modéstia e de sua humildade. $\mathrm{Na}$ medida em que ela sabe distinguir os seus domínios daqueles que pertencem a outras ciências e se dispõe a uma tensão crítica relativa aos seus procedimentos, permanece um instrumento de progresso, erigindo-se em verdadeira prestidigitação quando transpõe êstes limites e normas.

O propósito dêste trabalho é contribuir para o estabelecimento de uma distinção sociológica entre a política e a administração e sugerir um caminho para evitar o conflito entre ambas.

\section{I - O campo da administração e o da política}


Tanto a administração como a política podem ser consideradas como dois campos diversos ou como dois tipos diferentes de conduta.

Segundo Alberto Schaeff1e, é possível distinguir duas espécies de acontecimentos na vida social: acontecimentos que se repetem e para os quais existe já uma norma, e acontecimentos de índole nova que não se encaixam no sistema de previsões em vigência. Ao conjunto dos primeiros chama de "assuntos rotineiros do Estado" ou "administração" e ao conjunto dos segundos chama de "política" ${ }^{4}$.

É óbvio que o que modernamente se chama de administração é um campo muito menos extenso do que o indicado por Alberto Schaeff1e. Na expressão "assuntos rotineiros do Estado", se inclui também a prática de tôda e qualquer espécie de direito. Para o nosso propósito, porém, é melhor que assim seja. A vantagem desta distinção é, exatamente, delimitar, com clareza, um corte vertical na sociedade, separando uma zona dominada de outra cujas fôrças não foram ainda reguladas. Bem se vê que se trata de um esquema e, como esquema, de um mero artíficio heurístico.

Esta é uma distinção em absoluto acôrdo com o moderno conceito sociológico da sociedade. De fato, não se pode negar que cada dia verificamos o aparecimento de sucessos diante dos quais se mantêm inoperantes as regras já preparadas e que exigem do homem um esfôrco de racionalização. Em sociedades isoladas e pouco complexas, esta zona de acontecimentos se torna pouco percebida, mas em sociedades complexas como a industrial de nossos dias, a irrupção de acontecimentos rebeldes à norma prefixada é uma espécie de elaboração crônica.

Nas sociedades pre-letradas ${ }^{5}$; a zona do irracional é, senão inexistente, pràticamente pouco significativa. A vida do homem desta fase está inteiramente regulada por "mores" e "folkways", "tabús" e "totems", de modo que os impulsos irracionais pouco estímulo encontram para ocorrer. Tôda a existência humana transcorre dentro de estilos tradicionais cujo número e espécie são suficientes para preservar os grupos e o indivíduo de situações problemáticas. Nesta fase, não existe política e a administração está diluída na estrutura social.

Nas sociedades às quais se aplica o conceito de civilização, a maior ou menor importância daquelas zonas é função da constituição das classes. Quando estas se configuram de modo rígido, impedindo ou embaraçando a circulação vertical dos socii (Antiguidade, Idade Média, Regime Antigo) torna-se missão de uma classe dominante, que pode ser uma élite ou ser servida por uma élite, torna-se sua missão impedir que fatôres irracionais ameacem a estabilidade social. As classes inferiores, por falta de perspectiva, jazem imersas no conformismo e no Etnocentrismo. Por êste motivo, fica assegurado o primado da rotina ou da administração, num sentido lato, sôbre a política. É a desintegração social, promovida, freqüentemente, pela inter-comunicação de grupos diferentes ou pela decadência das élites, que concorre para minar aquêle primado da rotina e que torna urgente o apêlo à política. A importância desta última tende a crescer ainda mais à medida que as barreiras entre as classes desaparecem e o Estado se recorta do corpo social, deixando de ser uma entidade difusa para se constituir em instituição nítida. Com o aparecimento do Estado, a administração adquire consistência.

Nas sociedades modernas, não é difícil perceber a existência de uma zona cujos processos estão dominados ou racionalizados e de outra cujos processos constituem 
objeto da política. A organização da sociedade atual, cada vez mais submetida ao princípio democrático, concorre para que a política atue ordinàriamente como um subordinador da administração. Nêste particular, estamos diante de um fenômeno tipicamente moderno. A tendência da administração foi sempre, como mostrou Haroldo Laski, tornar-se uma classe privilegiada e não considerar os interêsses do Estado. Foi com o reconhecimento da legitimidade da opinião pública e com o desenvolvimento das agências de contrôle externo $^{6}$ e interno da administração, desde o parlamento até a imprensa, que ela renunciou à sua inclinação de organizar-se em casta.

$\mathrm{O}$ irracionalismo ${ }^{7}$ é, hoje, inerente à sociedade, uma vez que a competição é livre e as mais variadas idéias e emoções lutam entre si, pela adesão das maiorias que ditam aos govêrnos, pelo menos em princípio, as linhas decisivas de sua ação. $\mathrm{O}$ desenvolvimento da política decorrente da presença dêstes fatôres, não corresponde a uma atrofia da administração. Ao contrário, o seu campo cresceu paralelamente ao avanço da industrialização ${ }^{8}$.

\section{II - A conduta burocrática e a conduta política}

Até agora vimos considerando a política e a administração, de um modo, se me permitem, geométrico, isto é, como dois espaços distintos. Deve ser acentuado que uma e outra não são compartimentos estanques e que há uma íntima relação entre elas. A análise ficaria incompleta se não considerássemos os estados psicológicos associados a cada um dêstes dois setores do todo social. A política e a administração (e, neste caso, esta última é mais propriamente chamada burocracia) são ainda duas "formas de vida", duas experiências, duas cosmovisões, cada uma com característicos específicos. No livro famoso de Eduardo Spranger, o interessado poderá encontrar o estudo do homem político, sob um ângulo estritamente psicológico e em "Mirabeau, ó el político", Ortega y Gasset traça por sua vez, um perfil bastante válido do caráter político. Nosso intúito, porém, é sociológico e, por isto, ressaltaremos apenas os aspectos mais externos dos dois tipos de conduta ${ }^{10}$.

Ordinàriamente se conhece a caricatura da conduta burocrática. O burocrata, dizse, é um indivíduo formal, apegado a normas, regimentos, regulamentos e leis. Imputa-se-lhe uma incapacidade espiritual de compreender a rica variedade da vida. Seu espírito, diz-se, é de pedra, e até se poderia usar uma linguagem weberiana, dizendo-se que é estereotipado. Esta concepção vulgar da burocracia indica, de fato, certos aspectos que correspondem à realidade. Seu êrro consiste, contudo, em acentuar apenas o caráter negativo da burocracia, negligenciando o que encerra de positivo.

Sociologicamente, a burocracia, como atitude, se caracteriza por uma certa inflexibilidade ${ }^{11}$, pela resistência às mudanças e pela superestimação do statu quo. Sua tendência é admitir que a zona racional e a zona irracional da sociedade são homogêneas e, portanto, que a segunda pode ser tratada do mesmo modo que a primeira. Seu comportamento é "reprodutor", isto é, orientado no sentido de, em face de qualquer acontecimento, ainda que este seja uma revolução, apelar para as normas existentes. Em conseqüência disto, as transformações da esfera administrativa se operam lentamente ${ }^{12}$, causando, muitas vêzes, embaraços aos outros setores da vida social. Um exemplo disto é o que constitui a persistência de estatutos que perderam de todo 
a função, em virtude de transformações sofridas pelas situações a que se referiam. Aliás, o estudo da "demora" da administração brasileira, com relação aos outros departamentos da atividade do país (sobretudo do econômico) é tarefa que está exigindo a aplicação de um espírito denodado. As duas obras do Sr. Caio Prado Júnior, Formação do Brasil Contemporâneo e História Econômica do Brasil, são magníficos pontos de partida para este empreendimento.

Também a política, como a burocracia, tem a sua caricatura que a reduz a oportunismo e a sistemático desrespeito aos precedentes estabelecidos e consagrados. Ainda aqui o vulgo assinala notas legítimas da conduta política sem, entretanto, reconhecer o seu sentido positivo. De fato, tôda política é inclinada a tornar a administração instrumento de seus objetivos. Em todo país se observa uma fricção entre os motivos políticos do govêrno e as razões burocráticas. W. Ivon Jennings, em seu livro, The British Constitution, refere que os ministérios ingleses têm a sua ortodoxia que não deve ser violada. Quando um ministro pretende executar uma política ameaçadora desta ortodoxia, sofre uma espécie de surda sabotagem. O mesmo ocorre na França e ocorria na Alemanha antes do nazismo.

Esta consciência de propósitos da burocracia não é inteiramente condenável ${ }^{13}$. Sua presença, ao contrário, supõe a existência de um tipo de servidor público, altamente qualificado. Uma burocracia capaz de formular claramente os seus princípios é o melhor antídoto da improvisação política e do caudilhismo. É necessário que a administração saiba formular um corpo coerente de doutrina e se constitua em verdadeiro sistema para resistir aos embates do radicalismo político. Para isto, deve oferecer, em seus quadros, oportunidades para as vocações teóricas, isto é, para aqueles indivíduos que não se inclinam para a prática administrativa, mas para a pesquisa pura. Sem uma teoria, jamais a administração poderá tomar forma e fàcilmente se converte em débil prêsa do oportunismo.

O principal característico da política, entendida como conduta, é reconhecer a existência dos acontecimentos irracionais e admitir a possibilidade de dominá-los mediante uma inovação. Trata-se pois de uma conduta que não é estereotipada ou reprodutora. Não é demais lembrar que há circunstâncias em que é difícil distinguir as duas condutas. Muitas vêzes é do próprio seio da administração que partem as iniciativas de atos que devem modificar disposições caducas ou insuficientes - o que não invalida a distinção, uma vez que as modificações deverão ser decididas, conforme o sentido da política, estabelecida pelas autoridades competentes. À política está sempre associada uma índole de decidir, de assumir responsabilidade. Quando uma medida se manifesta na prática desacertada não é à burocracia que a elaborou que se deve imputar a sua responsabilidade, mas à política de que é veículo.

\section{III - A neutralidade política da burocracia}

Descobre-se, neste caso, a natureza da relação entre os dois modos de atuar e, ao mesmo tempo, um caminho para resolver o problema da neutralidade política do serviço civil. Os administradores modernos são unânimes em admiti-la como ideal e percebem que só dêste modo a administração pode ficar a salvo de expurgos intermitentes, por ocasião das mudanças de govêrno, e adquirir a estabilidade necessária para que o seu patrimônio técnico seja preservado.

Acentue-se que a administração só poderá ajustar-se às exigências da democracia, 
enquanto submeter-se ao princípio moral da neutralidade política. Portanto esta é uma questão básica.

\section{Como resolvê-la?}

Em primeiro lugar, é necessário colocála bem, da maneira menos equívoca possível. Que se entende por um serviço civil politicamente neutro? A nosso vêr, entende-se assim todo aquêle que, com absoluta lealdade e imparcialidade, põe os seus conhecimentos técnicos a serviço das diretrizes traçadas pelo govêrno. É uma definição que, provàvelmente não está isenta de defeitos, mas suficientemente clara para constituir um ponto de partida.

Da definição se conclui que a burocracia é um instrumento e consiste numa certa virtuosidade, nisto que está sempre disposta a dar forma e expressão aos propósitos dos govêrnos que se sucedem uns aos outros, periodicamente. Por isto, toda burocracia aparecerá sempre como a executora de uma política e, portanto, politicamente interessada. Um público deseducado não sabe, porém, distinguir a burocracia da política e, muitas vêzes, acusa repartições de erros que elas só poderiam ter evitado se traíssem o ideal da neutralidade. No Brasil, por exemplo, esta confusão conduz a lamentáveis resultados. Preliminarmente, se o público é incapaz de compreender a função instrumental da burocracia, é ociosa qualquer medida tendente a mantê-la neutra. Neste caso, dever-se-ia começar pela educação do público e habituá-lo a um novo modo de ver.

\section{Com respeito ao corpo de servido- res, como é possível resolver a questão da neutralidade?}

Uma das medidas mais conhecidas é a que consiste em preencher as posições de chefia com pessoas da confiança direta das autoridades competentes. Com êste expediente, é provável assegurar-se a coerência das diretrizes, mas fréqüentemente à custa de uma desastrosa diminuição da eficiên$\mathrm{cia}^{14}$, pois nem sempre o chefe da confiança dos seus superiores possui o equipamento técnico indispensável para dirigir a repartição que lhe é confiada. Como substituto deste expediente, tem-se advogado o incremento da profissão de administrador e a sua subordinação a um código de conduta ${ }^{15}$.

Uma outra medida é proibir que os servidores públicos exerçam atividades políti$\operatorname{cas}^{16}$. A lei Hatch é, nos Estados Unidos, um documento típico desta orientação.

Contudo, por maior que seja a eficácia das medidas restritivas mencionadas acima, jamais é suficientemente poderosa para extinguir o resíduo ideológico da conduta burocrática. A burocracia é uma condição existencial e, como tal, um determinante da consciência. Graças à sociologia do conhecimento sabe-se, hoje, que tôda modalidade de conduta é situacionalmente configurada. A burocracia, como as outras camadas sociais, encerra um conteúdo ideológico, isto é, está afetada de uma disposição a confundir sua perspectiva parcial com a perspectiva total da sociedade, donde provém o seu atrito com as outras correntes. A chamada ortodoxia das repartições é uma manifestação da ideologia burocrática. Sob a forma de ortodoxia, ela, muitas vêzes, embaraça, deturpa, compromete a execução da política do govêrno.

Se a ideologia é um produto inelutável das condições existenciais, ninguem poderá esperar que a burocracia atinja uma arquiangélica inocência. O que é possível é reduzir a um mínimo o resíduo ideológico de sua conduta. Para isto, ela deveria realizar uma auto-consciência de sua ín- 
dole e submeter as suas elaborações a uma crítica sociológica permanente.

Após a preparação técnica, seria aconselhável que o servidor fôsse provido de conhecimentos sociológicos concernentes ao seu campo de ação. Aqui se propõe um esbôço de programa que parece enfeixar, em linhas gerais, a matéria de que êle necessita para proceder àquela superação.

\section{IV - um programa de sociologia para técnicos de administração}

\section{I - Estudo da socialização}

1. Hereditariedade e ambiente. Indivíduo e pessoa.

2. Conceito sociológico de natureza humana.

3. Interação versus causa-e-efeito.

4. O processo social.

5. Isolamento e contato.

6. Tipos de interação: competição, conflito, acomodação e assimilação.

7. Conceito sociológico de contrôle social.

8. Primeira definição da sociologia.

\section{II - Teoria sociológica das trans- formações sociais}

9. Formas de sociabilidade das sociedades pre-letradas.

10. Formas de sociabilidade da sociedade antiga e da medieval.

11. Formas de sociabilidade da sociedade industrial.

12. Comunidade e sociedade.

13. Solidariedade mecânica e solidariedade orgânica.

14. A divisão do trabalho social.

15. A "anomia" e a heterogeneidade das condutas individuais.

16. A desorganização social, como um processo crônico.
17. O progresso da racionalização funcional.

18. A produção e o consumo da cultura.

19. A massa. O público. A "intelligentzia".

20. O princípio democrático e o Estado.

21. A planificação, como uma autodeterminação da sociedade.

22. Segunda definição da sociologia.

\section{III - Estudo sociológico da civili-} zação ocidental

23. Classe. Estamento. Partido. Sindicato.

24. A dominação carismática e suas formas.

25. O processo de rotinização do carisma.

26. A dominação tradicional e suas formas.

27. A dominação legal e suas formas.

28. A competição na esfera da vida espiritual.

29. O campo da administração e o da política.

30. A mentalidade utópica e a ideológica.

31. A ideologia burocrática.

32. A ideologia aristocrática.

33. A ideologia burguesa-liberal.

34. A ideologia marxista-comunista.

35. A ideologia fascista.

36. A possibilidade da sociologia política.

37. A sociologia da revolução.

38. Terceira definição da sociologia.

\section{IV- Estudo sociológico da crise}

39. A noção de "mudança estrutural".

40. Os tipos ideais.

41 O princípio da interdependência.

42. A sociologia da demora cultural.

43. A coetaneidade do não-coetâneo.

44. A auto-consciência da técnica.

45. O processo civilizatório. 
46. As implicações sociais e políticas da ciência.

47. A emergência da sociedade mundial.

48. A sociologia, como um instrumento de organização da sociedade.

49. O problema moral da sociologia.

50. Quarta definição da sociologia.

A primeira parte iniciará o estudante no conhecimento dos processos microscópicos da sociedade, no conhecimento indispensável daquilo que Jorge Simmel chamava de - socialização, das interrelações dinâmicas que ligam o indivíduo à sociedade e as partes desta entre si.

A segunda parte encerra os materiais para a formulação de uma teoria sociológica das transformações da sociedade. À diferença do modo de ver da história, diri- gido inteiramente para o particular, o sociológico procura as grandes categorias ou formas da sociabilidade características das várias etapas da civilização. Conhecendoas, o estudante se habituará a distinguir, em sua época, o que é vivo do que é morto ou parece viver.

A terceira parte é um estudo sociológico da civilização ocidental, principalmente à luz do método tipológico de Max Weber e da sociologia do conhecimento de Karl Mannheim.

A última parte é o estudo sociológico da crise. Seu objetivo é fornecer ao estudante os elementos necessários para que possa desenvolver um tipo de conduta em que os resíduos ideológicos estejam reduzidos a um mínimo.

\section{Notas}

${ }^{1}$ Para uma distinção de outro ponto de vista, cf. F. J. Goodnow, Politics and Administration, 1900. Consulte-se ainda o magnífico ensaio de Woodrow Wilson O estudo da administração na "Revista do Serviço Público", maio de 1946 e Marshall E. Dimock, O estudo da administração, na "Revista do Serviço Público", junho de 1946.

${ }^{2}$ Segundo C. H. Cooley, tôdas as atuais ciências da vida estão controladas pela idéia do desenvolvimento orgânico. No célebre ensaio, "The Roots of Social Knowledge", escreve: "Darwin gave these studies their orientation by making them studies of process rather than state, of what is going on rather than what is, of a drama than a picture" (In Sociological Theory and Social Research, 1930, pg. 306).

${ }^{3}$ A chamada sociologia da sociologia é um capítulo novo em que têm sido pioneiros José Medina Echavarría e Francisco Ayala.

${ }^{4}$ Esta distinção foi exposta no ensaio de Schaeffle, Uber den Wissenschaitlichen Begrifi der Politik, inserido em "Zeitschrift für die gesamte Staatswissenschaften", vol. 53, 1879 (citado por Karl Mannheim, Ideologia y Utopia, Fondo de Cultura Economica, México). Em virtude de não conhecermos o texto alemão e de estarmos baseando o nosso pensamento na exegese que dele faz Mannheim, vamos reproduzí-Ia: "O sociólogo e estadista austríaco Alberto Schaeffle afirma que em qualquer momento da vida político-social, se podem discernir dois aspectos: em primeiro lugar, uma série de acontecimentos sociais cuja norma se tornou fixa e que se repetem com regularidade; em segundo lugar, os acontecimentos que se acham ainda em processo de devenir nos quais, em casos individuais, se tem que tomar resoluções que produzem situações novas e únicas. Aos primeiros, deu o nome de "assuntos rotineiros do Estado", laufendes Staatsleben; aos segundos o de "política". O significado desta distinção se poderá ilustrar com alguns exemplos. 
Quando, na vida habitual de um funcionário, os assuntos correntes se dispõem de acôrdo com os regulamentos e normas vigentes, estamos, segundo, Shaeffle, no terreno da "administracão" antes que no da "política". A administração é o domínio em que podemos compreender, por meio de um exemplo o que entende Schaeffle por "assuntos rotineiros do Estado". Quando um novo caso, seja qual for, pode ser tratado conforme certos preceitos, achamo-nos não diante da política, mas de um aspecto estabelecido e recorrente da vida social. Schaeffle marca esta distinção com uma caríssima expressão, tirada do ramo da administração. Para os casos que podem ser tratados consultando meramente uma regra estabelecida, emprega a palavra alemã Schimmel, que se deriva do latim simile, com o que se quer exprimir que o caso será tratado de uma maneira semelhante ou similar a precedentes que já existem. Achamo-nos no ramo da política quando os enviados a países estrangeiros celebram tratados que nunca foram feitos antes; quando os representantes parlamentares fixam novas tarifas; quando subministram fundos para uma nova campanha eleitoral; quando certos grupos de oposição preparam uma rebelião ou organizam greves ou quando se reprimem estas, (Ideologia y Utopia, pg. 100)."

${ }^{5} \mathrm{O}$ adjetivo foi criado por Ellsworth Faris para substituir têrmos ambíguos, tais como: primitivo, inferior, selvagem, etc. O uso do vocábulo está sendo consagrado entre os sociólogos americanos e no Brasil foi introduzido por Donald Pierson. Diz E. Faris: "Preliterate" seems a better word. It is a neutral, connoting no reflection of inferiority, and is, therefore, objective and descriptive. Moreover, it may well be that the introduction of a written symbolic language is the chief differenciation between the culture of city-dwellers and those who belong to the "lower societies". But wether this be true or not, it is evident that none of peoples we include in the terms "savage" and "primitive" possesses a developed, written language. This is not because such a people cannot learn to read and write. Missionaries and teachers have proved that letters are not impossible to them. They have simply not had the opportunity to learn. They are not literate or iliterate.

Preliterate man is then one in whose culture there is no written language. (in The Nature of Human Nature, 1937, pgs. 252-3).

${ }^{6}$ Cf, sôbre contrôle da administração, Harvey Walker, Public Administration in the United States, 1937, pgs.99 e segs., e "Controles da Administração Pública", editorial in "Revista do Serviço Público”, maio de 1946.

${ }^{7}$ Cf. sôbre a acepção das palavras racional e irracional, Max Weber, Economia y Sociedad, vol. I, cap. I, edição do Fondo de Cultura Economica, México; Karl Mannheim, Libertad y Planificacion Social, Fondo de Cultura Econômica, México.

${ }^{8}$ Cr. sôbre o desenvolvimento da administração, o estudo de J. Donald Kingsley, "The Middle Class and The Evolution of Bureaucracy", inserido em seu livro, Representative Bureaucracy, 1944.

${ }^{9}$ In Tríptico. Colección Austral.

${ }^{10} \mathrm{O}$ leitor encontrará um equacionamento da questão semelhante ao nosso num estudo de C. J. Friedrich e Taylor Cole, "The Systematic Concept of Bureaucracy" (In Responsible Bureancracy, pags.9 e sgs.). Consulte-se ainda "The Characteristics of Bureaucracy" (In Bureaucracy and Trusteeship in Large Institutions, monografia escrita por MarshaJ E. Dimock e Howard K. Hyde para o Temporary National Economic Commitee).

${ }^{11}$ De Haroldo J. Laski: "The characteristics of such a regime are a passion for routine in administration, the sacrifice of flexibility to rule, delay in the making of decisions and a refusal to embark upon experiment. In extreme cases the members of a bureaucracy may become a hereditary caste manipulating government to their own advantage." (Artigo Bureaucracy, in "Enciclopaedia of the Social Sciences"). 
${ }^{12}$ De Haroldo J. Laski: "When rules have been in operation or when they have been made by men of considerable experience it is very difficult to resist their authority. Because they are old it is held that they embody necessary experience; and officials are not easily persuaded to abandon them." (Op. cit.).

13 “... since democracy implied also publicity, it was important too that there should be a uniform body of precedents, a consistent tradition, to which reference could be made in order to justify before a legislative assembly the action that was taken." (Haroldo J. Laski, in op. cit.).

${ }^{14}$ Sôbre os inconvenientes desta medida, manifestou-se recentemente o técnico de administração, Wagner Este'ita Campos, em artigo para esta Revista (número de junho de 1946), do qual destacamos êste trecho: "Não se deve subestimar, num grupo de trabalho, o extraordinário papel da direção; todos os seus componentes pedem ser elementos plenamente capazes, mas se a missão de orientar-lhes as atividades e articulá-las para um objetivo comum, programando, conduzindo, esclarecendo, controlando, dirigindo, enfim, é entregue a mãos menos capazes, o esfôrço conjunto pode ser prejudicado, quando não integralmente tornado inutil".

${ }^{15}$ É exemplo disto o Código de Ética adotado pela Associação Internacional de Administradores Municipais, assim estabelecido: I - Nenhum membro da profissão pleiteará ou aceitará um lugar de administrador municipal se não estiver inteiramente de acôrdo com os princípios da forma conselho-administrador, e se não estiver certo de possuir as qualificações necessárias para servir a êsses princípios, na qualidade de administrador municipal, em proveito da comunidade. II - O administrador municipal deve ter uma crença inflexível na dignidade e no valor dos serviços prestados pelo govêrno e um senso profundo de sua própria responsabilidade social, na sua qualidade de curador dos interêsses do público. III - O administrador municipal deve ser movido pelos mais elevados ideais de honra e de integridade em tôdas as suas relações públicas e pessoais, para que se torne merecedor do respeito e inspirador da confiança da organização que dirige e do público a que serve. IV - $\mathrm{O}$ administrador municipal deve estar seguro de que as honrarias e as vantagens pessoais conseguidas à custa de informações confidenciais ou de má aplicação do tempo são frutos de ação desonesta. V - O administrador municipal não é um orientador político. Para que a política municipal seja inteligente e eficaz, o máximo que o administrador pode fazer - e aliás deve fazer - é informar e aconselhar o corpo legislativo municipal e estimulá-lo a tomar decisões positivas. VI - O administrador municipal deve compreender que as decisões de caráter político cabem sempre ao conselho, isto é, aos representantes eleitos do povo e, por conseguinte, deixar a êsses a defesa das diretrizes que venham a sofrer crítica. VII - O administrador municipal deve manter a comunidade informada a respeito dos negócios do município, mas colocar-se sempre em segundo plano, acentuando a importância dos fatos, ao invés de focalizar a sua ação pessoal. VIII - Com o fim de preservar a sua integridade profissional, o administrador municipal deve resistir a tôda tentativa de interferência no seu contrô e pessoal, insistir no exercício do seu próprio julgamento no que toca ao cumprimento das diretrizes do conselho e tratar francamente com êste como órgão, evitando entendimentos secretos com seus membros individualmente. IX - $\mathrm{O}$ administrador municipal deve tratar tôdas as questões de pessoal à base exclusiva do mérito. Considerações de ordem política, religiosa, facial, não devem influir em nomeações, aumentos de salários e questões disciplinares. X $\mathrm{O}$ administrador municipal jamais deve dispensar favores pessoais. Éle deve trabalhar em benefício de tôda a comunidade e solucionar todos os problemas administrativos sem discriminação, à base de princípios e de justiça. (Vide "Formas de govêrno municipal nos Estados Unidos" in Revista do Serviço’ Público de dezembro de -944).

${ }^{16}$ Em seu trabalho, Neutralidade Política do Serviço Civil, H. Eliot Kaplan manifesta-se um entusiasta deste tipo de medida. "Liberdade para o servidor civil - diz - deve significar fidelidade unicamente ao govêrno, e não a qualquer organização política partidária. Aquilo de que mais 
precisamos em nossa democracia é de um serviço público imparcial, desinteressado e desprendido - um serviço público que represente o serviço civil do povo, e não o serviço do partido político ocasionalmente no poder. Na realidade, a própria natureza dos serviços governamentais de hoje em dia, com as novas repartições de caráter social criadas sob a injunção dos programas de bem-estar social e econômico da última década, mais do que nunca exige uma administração imparcial dessas repartições. A eliminação de atividade política indébita por parte dos servidores públicos tornou-se agora imperativa. (Separata da "Revista do Serviço Público", agôsto de 1945). 